African Journal of Business Management Vol. 6(50), pp. 12005-12015, 19 December, 2012

Available online at http://www.academicjournals.org/AJBM

DOI: $10.5897 / A J B M 11.2565$

ISSN 1993-8233 @2012 Academic Journals

Full Length Research Paper

\title{
HeXie management theory and sustainable development
}

\author{
Hui He*, Nelson António and Virginia Trigo \\ Management department, ISCTE-IUL Instituto Superior de Ciências do Trabalho e da Empresa - Instituto Universitario \\ de Lisboa, Portugal.
}

Accepted 31 August, 2012

\begin{abstract}
The sustainable development between human and nature is the scientific development view laid down and emphasized in the Third Plenary Session of the Sixteenth Central Committee of Chinese Party. This paper looks for preliminary ideas on frameworks for analysing sustainbale development. It first discusses the concept of sustainable development and the potential contradictions of three pillars of sustainability on the basis of the evironment protection, economic development and social progress. Based on this conceptualisation of sustainable development, it then goes on to introduce the latest management tool, HeXie Management Theory and "Dual-Principles" mechanism. Through questionnaires and data analysis we demenstrates HeXie management theory is an adequte tool combining the both aspects of strengthening government management and inspiriting enterprise subjective initiative to solve these internal interacting contradictions and to achieve the sustainable development simultaneously.
\end{abstract}

Key words: HeXie management theory, "dual-principles" mechanism, sustainable development, China.

\section{INTRODUCTION}

During the 1980s, a growing literature on sustainable development has tried to reconcile the contradiction between economic development and environmental preservation (Novek and Kampen, 1992). China is experiencing the similar situation. So far the Chinese path has been a remarkable success with an average annual growth rate of $11.9 \%$ in gross domestic product (GDP) from 1979 to 2007. In 2008 and 2009, due to the financial crisis, China witnessed the lowest GDP 9.6 and $8.7 \%$. According to the lastest statistics the GDP in the first quarter of 2010 has risen back to $11.9 \%$. However, rapid industrialization has put citizens and ecosystems at risk in China. The problem of the environmental degradation is becoming serious. The World Bank examined 20 of the most severely polluted cities in the world in 2006. Sixteen of these cities are located in China, and

\footnotetext{
*Corresponding author. E-mail: amberhehui@hotmail.com.
}

Linfen City, in Shanxi Province, was cited as the world's most polluted city. The problem of air pollution in China's cities remains serious. In $2005,39.7 \%$ of the 522 cities surveyed were either moderately or seriously polluted.

China's leadership is increasingly aware of the growing environment issues. Pan Yue, vice director of the State Environmental Protection Administration of China said, "Environmental problems have become a main factor affecting China's national security and social stability." The efforts also were illustrated by the leadership's decision following a series of conferences on science, sustainable development and policy, such as the China Agenda 21, Boao Forum for Asia in 2010, the latest 2010 annual scientific session of the environment protection plan convented on May 5 in Shanghai, China. All these sessions themed as "Green Recovery: Asia's Realistic Choice for Sustainable Growth" and discussed the implementing programmes in the China Twelfth Five-Year Plan. Whereas sustainable development is shaped by many interrelated factors. 


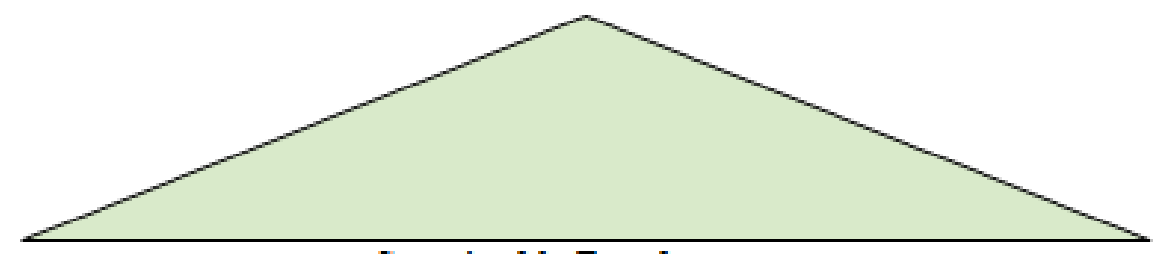

Sustainable Development

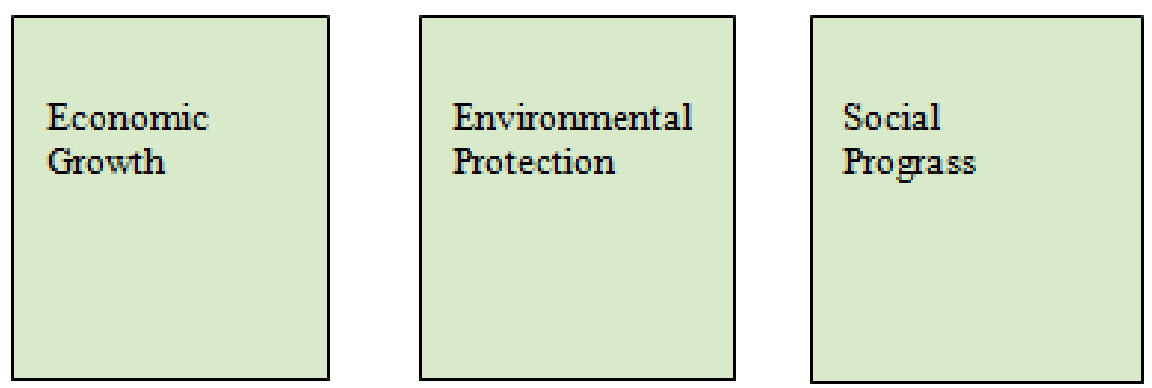

Figure 1. The "three pillars" of sustainability (Adams, 2006).

The relationship between economic expansion and environmental preservation remains fundamentally contradictory (Novek and Kampen, 1992). Hahtola (1990) and Norgaard (1994) point out that social or economic aspects may be the most relevant and meaningful points of departure as long as the operation of socioeconomic systems does not enter into conflict with the environmental frame-work conditions (Shen and Lu, 2004) put forward the "environment is a typical quasi-public goods" in which they address the crucial role of organization and authority in public goods provision and management.

Public goods provide a very important example of market failure, in which market-like behavior of individual gain-seeking does not produce efficient results. The production of public goods results in positive externalities which are not remunerated. If private organizations do not reap all the benefits of a public good which they have produced, their incentives to produce it voluntarily might be insufficient. Environmental preservation requires nonmarket intervention to counter the commodification of resources and to protect them from market pressure. Such non-market interventions, however, restrict economic growth and illustrate the contradictory commitments of governments to economic expansion and environmental protection (Redclift, 1987).

Given the complexities of the sustainable development between environment and economy this paper tries to employ HeXie management theory which is especially useful for complicated and volatile management issues after a systematicly analysis of the internal contradictions in sustainble development. HeXie management theory, which fully absorbs the harmony thought of Chinese traditional culture and the latest development of manage- ment researches, is trying to build a new management model which has a new understanding on the organization management.

\section{THE CONCEPTION OF SUSTAINABLE DEVELOPMENT}

The terminology of sustainable development agreed by most ethicists is that of the Brundtland Commission of the United Nations on March 20, 1987: "Sustainable development is development that meets the needs of the present without compromising the ability of future generations to meet their own needs". Accordingly, sustainable development is development that reaches or maintains a sustainable state (Ott, 2003). At the 2005 World Summit, it was noted that this requires the reconciliation of environmental protection, social progress and economic growth demands the "three pillars" of sustainability (Adams, 2006) (Figure 1). Since the Rio conference in 1992, this tripartite description has constituted the basis for most of the generally accepted definitions of sustainable development in international organisations (OECD, 2001b; Commission of the European Communities, 2001), called 'triple bottom line' in the business circles (Markku, 2004).

The environmental protection dimension has commonly been recognised as the weakest 'pillar' of susutainable development, notabley when it comes to its analytical and theroetical underinnings. While increasing attention has lately been paid to the interaction between economic development, environmental protection and social progress still remains a largely uncharted terrain. 
Much less consensus reigns over the ralations among the dimensions. Markku (2004) argues that each of the three 'pillars' has its own characteristics and logic, which are likely to conflict with each other. The model does not give any guidance on how to arbitrate between the unavoidably conflicting objectives of economic rationality (profitability), social justice and ecological equilibrium. Some researches (Case and Fair, 2006; Jared, 2006) argue that economic growth, combined with globalization, is creating a scenario where we could see a systemic collapse of our planet's natural resources. In this model, the three pillars have been replaced by three concentric circles, the environment circumscribing the social dimension, and the economic sphere constituting the innermost circle. This reflects the idea that economic activities should be in the service of all human beings while at the same time safeguarding the biophysical systems necessary for human existence. The social would thus be in the command of the economic, but at the same time submitted to the ultimate environmental constraints (Markku, 2004; Passet, 1996; Mare'chal, 2000). In China economic is growing rapidly, but the energy consumption is increased even surpassing the rate of economic growth. From 2002 the energy elasticity coefficient was over 1. In 2004, China's energy elasticity coefficient has risen to 1.6. The elasticity in 2005 was 1.02 and 0.87 in 2006.

\section{Environment and economy interface}

The root reasons of the contradiction between environment and economy are the public goods feature of environment and the externality feature of economic. Public goods are defined by two factors; (1) Non-rivalry that consumption of the good by one individual does not reduce availability of the good for consumption by others, (2) and non-excludability that no one can be effectively excluded from using the good (Hal, 1991; Mas-Colell et al., 1995). Environmental problems are seen as examples of 'market failure': cases where markets fail to achieve their otherwise socially optimal result. This failure arises because environmental goods are not priced and consumed collectively. If private organizations do not reap all the benefits of a public good which they have produced, their incentives to produce it voluntarily might be insufficient. Consumers also can take advantage of public goods without contributing sufficiently to their creation (Michael, 1997).

In addition, in a competitive market, producers may not bear all of the costs or not reap all of the benefits of the economic activity. This is called "externality" (Arthur, 1920). The negative externality is an action of a product on consumers that imposes a negative side effect on a third party. For example, manufacturing that causes air pollution imposes costs on the whole society. Many negative externalities are related to the environmental consequences of production and use, such as water pollution by industries that adds poisons to the water, which harm plants, animals, and humans. The Stern (2007) review on the Economics of Climate Change says "climate change presents a unique challenge for economics: It is the greatest example of market failure we have ever seen". Consequently, the economic entities are the makers of environment degradation and therefore have the main duty to participate the process of environmental sustainable development.

Considering the inherent contradiction between environment and economic development, many economists would like to seek a modulatory method to manage this issue.

Canadian scientist, David Suzuki stated that ecologies can only sustain typically about 1.5 to $3 \%$ new growth per year, and thus any requirement for greater returns will necessarily cannibalize the natural capital. Economist Keynes claimed that market failure need the active governmental participation in the process of monitor and motivate to enterprises (Keynes, 1936). Coase (1974) introduces the concept of "transaction costs" to explain the nature and limits of firms, and "the problem of social cost" (Coase, 1960), which suggests that if the transaction costs are zero, institute (all kinds of rule and regulations) is abundant; whereas if transaction costs are not zero institute is important. James Tobin developed the ideas of Keynesian economics, and advocated government intervention to stabilize output and avoid recessions. Given the important significance of governemnt, we moves to preveil the relationship between society and ecological economic development.

\section{Society interface of sustainable development}

The interaction between the social and environmental dimensions is probably the least developed notably when it comes to measurement of sustainable development (OECD, 2001b). Social progress is the idea that societies can or do improve in terms of their social, political, and economic structures. The frameworks for analysing the links between the social and the other dimensions are in short supply. One applied theoretical model in terms of social-sustainable development interface consists four key concepts: Environmental quality, social quality, environmental policy and social policy. Social quality is defined as "the objectifiable and subjective aspects of society which direct people's well-being" (Coenen et al., 2000).

The overall simple concept shows that the indicators are weak to reflect the complicated interactions and neglect the economic dimension. On the other side, this study offers two meanful points. First it questions that the traditional linear models of cause and effect relationships 
is poorly adapted to analysing the complex social phenomena. The coevolutionary framework might be a good candidate for a more adequate analytical model. Second, it contributes an idea of utlizing the function of social aspect, social policy or government policy to control environmental protection. Likewise this viewpoint has been demonstrated time after time. Social policy was already a essential way to protect envionment and promote economy (Mary et al., 2008; Helmut and Martin, 2002).

Given the previous discussion, we summarize three points, government policy, enterprises' initiative and its coevaluation. Based on this conclusion, we consider HeXie management theory as a feisible and desireble method. Subsequently, the study introduces the conception of HeXie management theory and "dual-principles" mechanism.

\section{HEXIE MANAGEMENT THEORY AND DUAL- PRINCIPLES MECHANISM}

As Einstein once said, "If you do not believe in the harmony inside of our world, there is no science at all". Plenty of harmony thinkings theoratically and practically exist in management field. For instance, Andrew (1835), a vanguard in management field, have attampted to find an solution which could prevent disorganized mess in factory led by each individual's different way of working.

According to the viewpoint of Andrew Ure, every enterprise has three principles of action and three organic systems -- "mechanical, moral, commercial" so that to achieve the harmony to the whole.

In the 19th century, French famous economist, Claude Frédéric Bastiat published a book, Harmonies économiques (1851). Claude thinks that the general principles of the world are harmonious compatibility and these principles tend to make human improvement. Likewise, for human or human society, harmony does not mean perfect but improvement. Bastiat advocates free trade model and views society as exchanges in which to produce harmonious society. One polish top manager and scholar Karol Adamowsky, clearly identified the rudiment of "harmony theroy" and based on this theroy he simply explaned some rules of plan and control in terms of management science. Furthermore, Karol put foreward a harmonious system and illustrated some complex relations of interactions among each work to insure a harmonious cooperation.

In Japan, Tom Peters, Robert Waterman and Phillip published their 7-S-Model in their article "Structure Is Not Organization" (1980) and "In Search of Excellence" (1982). Pascale and Athos in "The Art of Japanese Management" (1981), The Seven-Ss is a framework for analyzing organizations and their effectiveness. It looks at the seven key elements that make the organizations successful, or not: strategy, structure, systems, style, skills; staff; and shared values. Those seven elements are distinguished in so called hard S's and soft S's. The model shows that organizational immune systems and the many interconnected variables involved make change complex, and that an effective change effort must address many of these issues simultaneously.

Currently, there are plenty of thinking related to harmony, such as, systematic, dynamic, contingent or evolutional ideas. Itami (1987) pointed out an concept called "dynamic adaptive principle". Itami (1987) observed manager's role is to create consistency among disorder condition and to make strategy, system and procedure consistent. Quinn (1988); Hart and Quinn (1993); Hart and Banbury (1994) cliamed strategy managment needed to balance those contradiction in organization, like the relation between broad vision and each action, flexible and stable. Fiegenbaum et al. (1996) stated a strategic reference point theory and set a SRP matrix to control the contradictions between action and objective. In China, Wang et al. (1998) suggested a flexible strategy emphasizing enterprise should make plan or strategy to adapt, utilize and create changes forwardly. Since enterprise is an open and complex system, we should adapt systematic viewpoint to deal with related problems.

On the whole, harmony thinking can be viewed as an general operational mechanism reflecting economic society and exits in the evolutionary processes of management science. But irrespective the ancient or neoteric management schools, it has been always staying in fragmentary condition but never become a standard scientific management theory due to the limitation of the level of scientific development.

In 1987, with the book "HeXie (Harmony) Theory and Strategy" published, Xi Youming, a Chinese management science scholar, brought forward a conception, "HeXie (harmony) Theory", combining the essences of both Chinese and Western management theories. The Chinese characters "HeXie" stand for the core thought in Chinese traditional culture. It means the unification of effectiveness and spiritual fufilment. In the management context, "HeXie theory" reflects four perspectives, internal harmony, external harmony, technology harmony and spiritual harmony. In particular, spiritual harmony is the compatibility of the goals between enterprise's and individual's, or between each individuals. Technology harmony includes the legitimacy of organizations, the effectiveness of allocation of resources and the techonological advance and reasonableness.

Furthermore, the techololy harmony and spiritual harmony have certain relationship because all actions are made by people, the effectiveness does not only rely on technological reasonableness but also on individuals' performance. Gathering these two kinds of harmony with internal and external harmony we draw a new combination. 
Taking enterprise as an example: "Internal Spiritual Harmony" means a solid enterprise culture that owners, managers and employees have relatively consistent value and behaviour orientation. "External Spiritual Harmony" means the degree of compatibility between enterprise's culture and social culture. "Internal Technology Harmony" indicates the efficiency of allocation of all factors of production, such as advanced technology and management method. "External Technology Harmony" is the capability in exchanging informations and materials with external environment.

In summary, the fundamental idea of "HeXie Management Theory" emphasize the overall harmony and the consistency between inside and outside of enterprise. This model is a tool for managerial analysis and action that provides a structure with which to consider a company as a whole, so that the organization's problems may be diagnosed and a strategy may be developed and implemented. This idea illustrates the multiplicity interconnectedness of elements that define an organization's ability to change. The theory helped to change manager's thinking about how companies could be improved. It says that it is not just a matter of devising a new strategy and following it through nor is it a matter of setting up new systems and letting them generate improvements. Based on these, $\mathrm{Xi}$ Youmin establishes a framework, "DualPrinciples" mechanism. Question-oriented measure is adopted and the conception harmony theme he call "HeXie Theme" is introduced. He defines "HeXie Theme" is the core objective or long-terms goals of enterprise constrained by internal and external envionment. These influencing factors from internal and external area are classified into two elements; He principle and Xie principle. "He Principle" is used to inspire the creativity of individuals to resolve uncertainty, while "Xie Principle" focuses on scientific design and optimization under relatively certain conditions. "He principle" can inspire the positivity and creativity of individuals to adapt the environment's change and accomplish those tasks which cannot be regulated in advance effectively. "Xie principle" performs management tasks by presenting specific behavioral path in advance in the sense of cost-benefit analysis.

The "dual-principles" mechanism is dynamic and evolutive process in which He principle and Xie principle under HeXie theme adjust to each other at the different level of the organizational network. It is HeXie coupling that helps inducement evolution and rational design realize the dynamic coherence of organization as a whole. HeXie coupling should follow three rules. Firstly, He principle and Xie principle that directed by the HeXie theme should interact and fit rather than separate each other. Secondly, the problems which should be solved by $\mathrm{He}$ principle originally can be solved by Xie principle when manager know the law of causation, and $\mathrm{He}$ principle should find new ways to solve the problems caused by people's activity and creativity in the process of using Xie principle, that is, He principle and Xie principle can convert each other under some condition. Thirdly, the mechanism of HeXie coupling is characterized by "adaptive walk" among local optimality and global optimality, and complexity to be worthy of being taken into account emerge from the coupling.

The key of HeXie coupling is aiming to solve the problem that how to make the two legs congruously and orderly to walk with steadiness and sound speed. Manager should organically combine the two principles to achieve better performance. According to the previous discussion, it is clear that sustainable development is a complex system combining with series of closely connected and interdependent factors. Environmental protection, economic growth and society factors are main factors for the composure of the complex system. This article builds up "dual-principles" mechanism integrated government management with enterprises' subjective initiative for environmental and economic sustainable development.

\section{RESEARCH METHODOLOGY AND DATA COLLECTION}

By adopting the method of combining the interview and questionnaire, we investigate the main influence factors of environmental protection and economic development in the enterprise level and analyzing the applicability of HeXie management theory and "Dual-Principles" mechanism frame in the aera of sustainable development.

To combine two research methods is because two reason; First, HeXie management theory is in practical exploratory stage although it HeXie management theory has been developed further from conception to mechanism. The study on embedding HeXie theory in practical matters is still insufficient. Meanwhile interview method offer a way of looking deeply into the enterprises and their viewpoints and real activities when confronting of the contradiction of environment and economic development. Second, using interview method only offers small scale and small samples which lacks universality. Therefore, we chose interview method integrating with questionnaire method.

\section{Interview and material collection}

The qualitative research interview seeks to describe and the meanings of central themes in the life world of the subjects (Kvale, 1996). Interviews are particularly useful for getting the story behind a participant's experiences. The interviewer can pursue in-depth information around the topic. Interviews may be useful as follow-up to certain respondents to questionnaires to further investigate their responses. (McNamara, 1999). We use informal, conversational interview and open-ended questions in order to remain as open and adaptable as possible to the interviewee's nature and priorities and to facilitate faster interviews that can be more easily analyzed and compared.

Based on previous method, we interviewed five enterprises with informal conversation and open-end questions. The core is to investigate those enterprises' attitudes, activities, concerns when doing commercial and environmental protection activities.

Specifically, material collection will be around following four aspects: 
Table 1. Enterprises basic information.

\begin{tabular}{|c|c|c|c|c|}
\hline $\begin{array}{c}\text { Name of } \\
\text { enterprise }\end{array}$ & $\begin{array}{c}\text { Date of } \\
\text { establishment }\end{array}$ & Nature & Scope of business & $\begin{array}{l}\text { Number of } \\
\text { employee }\end{array}$ \\
\hline A & 1998 & State-owned & $\begin{array}{l}\text { hydro-electric power station construction } \\
\text { and management }\end{array}$ & $>10000$ \\
\hline $\mathrm{B}$ & 1988 & $\begin{array}{l}\text { Private and } \\
\text { multinational }\end{array}$ & telecommunication products & $>80000$ \\
\hline C & 1984 & $\begin{array}{l}\text { Private and } \\
\text { multinational }\end{array}$ & $\begin{array}{l}\text { Electrical household appliances; IT } \\
\text { products; Medicine facilities }\end{array}$ & $>60000$ \\
\hline $\mathrm{D}$ & 2001 & SME & House products & $>700$ \\
\hline$E$ & 2006 & SME & Energy-saving products & $<100$ \\
\hline
\end{tabular}

Annotation: For avoiding reveal relative information we use $A, B$...instead of the names of enterprises.

1. Environmental consciousness of entrepreneurs.

2. Environmental protection monitor and environmental information disclosure.

3. The degree of concern on environmental technology innovation as well as effective.

4. Constrain from International Corporation.

The interviewees included senior managers, shareholders or top financial managers. Each interview sustained 30 to $90 \mathrm{~min}$. Meanwhile we collected relative informations of these five enterprises. Enterprises' basic informations are showed in Table 1.

\section{Questionnaires survey}

For further validating the reliability of this study and verifying the practicability of HeXie management "dual principles" mechanism, according to the result of in-depth interview and material collection, we worked out the respective questionnaires, then conducted the survey.

\section{Material and data analysis}

\section{Interview material analysis}

Through in-depth interview in enterprises and the classification research on material and data, we found the interviewees from different enterprises in different scale and nature have various attitude and activities (Table 2).

In sum, the previous enterprises statement different strategic priorities due diversity resources that they have, like governmental support and supervision, products properties, financial strength. Although the main attitudes and activities are not all the same, their focal concerns can be described in terms of the following categories.

1. Governmental intervention including dissemination of environmental consciousness, implementation and supervision. All enterprises try to upgrade their quality to the relative standards required by government.

2. The developing stages of the enterprises. This condition influent directly environmental behaviors.
3. International corporation. Globalization has positive effects on the environment because it increases institutional and customer pressures on firms to surpass local requirements, even when they may be tempted by lax regulations and enforcement in countries offering themselves as pollution havens (Hoffman, 1999; Rugman and Verbeke, 1998).

4. Corporate culture. Green corporate culture integrates environmental conception to strategic planning, production links, commercial activities, consequently, gain core competence.

From material analysis, whatever from national level or enterprise level, all presentations like laws and regulations, international corporate, technology innovation, financial investment, strategic planning and corporate culture, can be interpreted as two directions of "He principle" and "Xie principle". In other words, to combine the national standardized management with motivating entrepreneurs' initiative is a approach to sustainable development. According to the preliminary discussion, HeXie management and "dualprinciples" is appropriate solution. Also, based on the result, we designed a questionnaire (Table 3) for the further investigation on large samples.

\section{Questionnaire data analysis}

\section{Basic information}

From November 2009, we began to send this questionnaire to senior managers or at least managers of main department of enterprises. Samples were collected from EMBA and MBA students from UESTC, Xidian University and NWPU who are from all parts of China and from all walks of life so that these samples were broadly representative of Chinese situation. Until 1st May 2010, we collected 122 questionnaires. To exclude invalid questionnaires, 106 questionnaires are effective. These include 38 private enterprises and 68 stated-owned enterprises.

\section{Factor analysis}

For investigate if HeXie management "dual-principles" mechanism is appropriate way to resolve the contradiction between environ- 
Table 2. Entrepreneurs' views on environment responsibility and their activities.

\begin{tabular}{|c|c|}
\hline Name of enterprise & Attitudes and activities \\
\hline A & $\begin{array}{l}\text { 1. See environmental issue from strategic viewpoint and implement in every work procedures. } 2 \text { Stick } \\
\text { with environmental friendly development, attach great attention to ecology environment protection } \\
\text { issues, make the best of environmental protection and development, emphasize technology } \\
\text { innovation. 3. Strictly keep to national and international environmental laws and regulations as well as } \\
\text { accept professional project assessment. } 4 \text {. Environment investment accounts for } 2-3 \% \text { of the total } \\
\text { investment of each project. } 4 \text {. Transparent environmental information reports and disclosure. } 5 \text {. } \\
\text { internal and external supervision. }\end{array}$ \\
\hline B & $\begin{array}{l}\text { 1. Put environmental issue to strategic planning. 2. Green enterprise culture. } 3 \text {. Concern } \\
\text { environmental protection in the process of product development and production, material selection, } \\
\text { commercial activities. } 4 \text {. Implement internationalized management ISO 14001:2004, OHSAS } \\
\text { 18001:1999. 5. Transparent environmental information reports and disclosure. }\end{array}$ \\
\hline C & $\begin{array}{l}\text { 1. See environmental issue from strategic viewpoint. } 2 \text {. Control every production links, such as safe } \\
\text { and energy saving work place, green technology, green raw materials, green recovery. } 3 \text {. Research } \\
\text { and develop zero carbon products. } 4 \text {. Observe national and international industry standard, } \\
\text { environmental laws and regulations. } 5 \text {. Offering clear environmental information disclosure. } 6 \text {. Has } \\
\text { garnered high recognition and economic reward. }\end{array}$ \\
\hline $\mathrm{D}$ & $\begin{array}{l}\text { 1. Due to national policies's emphasis environmental consciousness is being increased. } 2 \text {. To meet } \\
\text { industry require standards. 3. Research and develop low-carbon products. }\end{array}$ \\
\hline$E$ & $\begin{array}{l}\text { 1. The most crucial responsibility of enterprises is to pursuit for interests. } 2 \text {. Survival is the first } \\
\text { objective. } 3 \text {. Obey the national relative policies. } 3 \text {. Following national policy to find commercial } \\
\text { opportunity. } 4 \text {. Offering energy saving products. } 5 \text {. Is preparing to apply products' international } \\
\text { certification.5. Has not other proactive activities. }\end{array}$ \\
\hline
\end{tabular}

Table 3. Questions of questionnaire.

\section{Questions}

01 . Does your enterprise adopt environmental protection Policies?

02. Does your enterprise accept supervision from internal or external of enterprises?

03. Does your enterprise recycle and recovery resources?

04. Has your enterprise saved money by reducing environmental impact?

05. Does your enterprise concern the potential environmental impacts when developing new products and services?

06. Has your enterprise gained competitive advantages by using the sustainability of its products and services?

07. Does your enterprise offer clear environmental information disclosure and reports for consumers

08. Has your enterprise upgrade environmental protection requirement due to international corporate?

09. Would your establish green culture associating with every business links if had international corporate?

\section{Degree of attention} (5 is the most concern)

1

2

1

2

3

3

4

5

5

1
1

1

1

1

1

2

3

4

5
2

4 
Table 4. KMO and Bartlett's Test.

\begin{tabular}{llc}
\hline KMO and Bartlett's test & & \\
\hline Kaiser-Meyer-Olkin measure of sampling adequacy & & 0.761 \\
& & \\
& Approx. Chi-square & 418.047 \\
Bartlett's test of sphericity & $\mathrm{df}$ & 36 \\
& Sig. & 0.000 \\
\hline
\end{tabular}

Table 5. Total variance explained.

\begin{tabular}{ccccc}
\hline \multirow{2}{*}{ Component } & Initial Eigen value & \multicolumn{3}{c}{ Extraction sums of squared loading } \\
\cline { 2 - 5 } & Total & $\begin{array}{c}\text { Percentage of } \\
\text { variance }\end{array}$ & $\begin{array}{c}\text { Cumulative } \\
(\%)\end{array}$ & Total \\
\hline 1 & 3.897 & 43.296 & 43.296 \\
2 & 1.808 & 20.087 & 63.383 \\
& 3 & 0.958 & 10.640 & 74.023 \\
Dimension & 4 & 0.610 & 6.783 & 80.806 \\
& 5 & 0.491 & 5.457 & 86.263 \\
& 6 & 0.386 & 4.290 & 90.553 \\
& 7 & 0.355 & 3.947 & 94.500 \\
& 8 & 0.306 & 3.399 & 97.899 \\
& 9 & 0.189 & 2.101 & 100.000 \\
\hline
\end{tabular}

Extraction method: principal component analysis.

ment and economic, it is necessary to explore questionnaire's structure. We applied predictive analytics software (PASW Statistics 18.0). Factors analysis method was adopted.

The Barlett's Test showed (Table 4) that Bartlett's value is 418.047; $\mathrm{P}<0.01$ and $\mathrm{KMO}$ measure of sampling adequacy is 0.761 (>0.7). That means these variables can accept factors analysis. (Kaiser, 1974). After the analytic approach of principal component analysis, two factors were gotten (Table 5, Figure 2 ). The total variance explained reaches $63.383 \%$. That means all variables can be explained by two factors (Zhang, 2002).

According to the result of factor analysis, variables var001, var002, var003, var004, var005, var006 and var007 belong to factor 1 , whereas var008 and var009 belong to factor 2 (Table 6).

\section{RESULT AND DISCUSSIONS}

Based on each factors' significance and the result of interviews and materials, it is fit to regard these two factors as "Xie principle" and "He principle".

Factor 1: "Xie principle" focuses on scientific design and optimization under relatively certain conditions. It mainly includes environmental protection policies (var001), supervision from internal or external of enterprises (var002), production procedure control (var003 and var004), strategic planning perspective (var005 and var006), and environmental information disclosure (var007). It is obvious that the seven variables related to relatively certain conditions, like government policies, supervision and enterprise's strategic plan.

Factor 2: "He principle" is used to inspire the creativity of individuals to resolve uncertainty. Here it includes var008 and var009. They illustrate that the enterprises' selfregulation to environment is due to the influence from international corporate enterprise. It is a representation of enterprise's subjective initiative.

Besides, the absolute values of the coefficient of var007 to two factors are respectively, 0.602 and 0.410 , which tells, var007 should be classified to factor 1 , but to some extent var007 also is affected by factor 2 . It is understood that environmental information disclosure is decided by "Xie Principle" (mainly government management) and "He principle" (mainly enterprise's subjective initiative).

The result of factor analysis clarifies that when dealing with the contradiction between environment protection and economic development, HeXie management is an alternative solution. Using "Xie principle" and "He principle" double mechanism will vail to intensify the inspiriting and self-restriction to enterprises in practice activities. Two principle influence each other so that generate coupling effect, in turn promote the achievement 


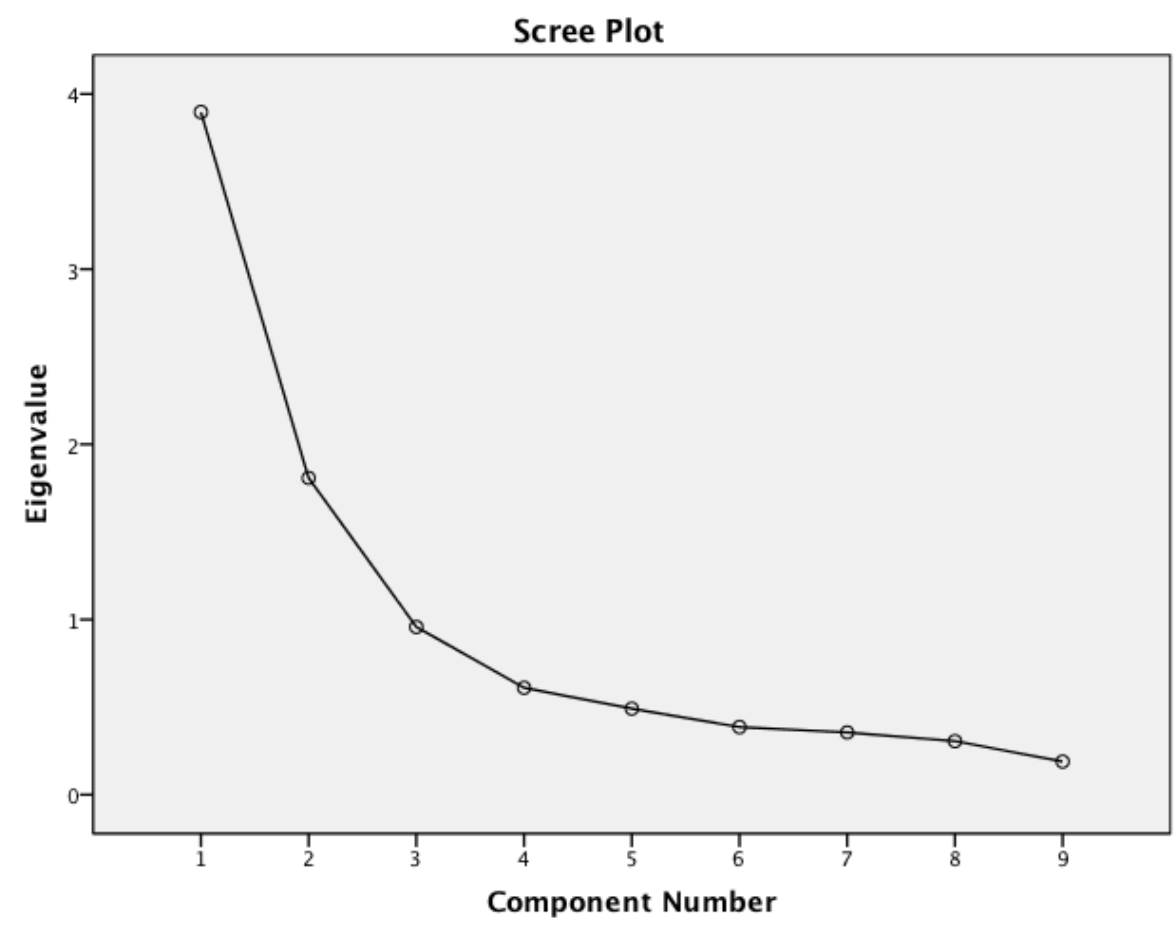

Figure 2. Scree plot.

Table 6. Component matrix ${ }^{\mathrm{a}}$.

\begin{tabular}{ccc}
\hline \multirow{2}{*}{ Variable } & \multicolumn{2}{c}{ Component } \\
\cline { 2 - 3 } & $\mathbf{1}$ & $\mathbf{2}$ \\
\hline var001 & 0.721 & 0.247 \\
var002 & 0.709 & 0.159 \\
var003 & 0.771 & -0.066 \\
var004 & 0.747 & -0.169 \\
var005 & 0.824 & -0.209 \\
var006 & 0.657 & -0.399 \\
var007 & 0.602 & -0.410 \\
var008 & 0.307 & 0.825 \\
var009 & 0.394 & 0.798 \\
\hline
\end{tabular}

Extraction method: principal component analysis. a. 2 components extracted.

of harmonious development (Figure 3).

From Figure 3, we can see the coupling effect of government management and enterprise's subjective initiative mainly includes the following three aspects. (1) "Dual-principles" mechanism is interactive. (2) "Dualprinciples" mechanism is interconvertible. (3) "Dualprinciples" mechanism integrates organically (Table 7).

Based on analyzing systematically the root reason to the contradiction between environmental protection, economic development and social progress, we suggested that HeXie management theories and "dualprinciples" mechanism are appropriate instrument to modulate and balance the conflict in the process of Chinese sustainable development. From the statistics result of questionnaire, we found and summarized the key contents of "dual-principies". Each principle must be consistent with and reinforce the other. Two aspects are interrelated, so a change in one has a ripple effect on another. It is impossible to make progress on anyone without making progress. Thus, to achieve your long- 


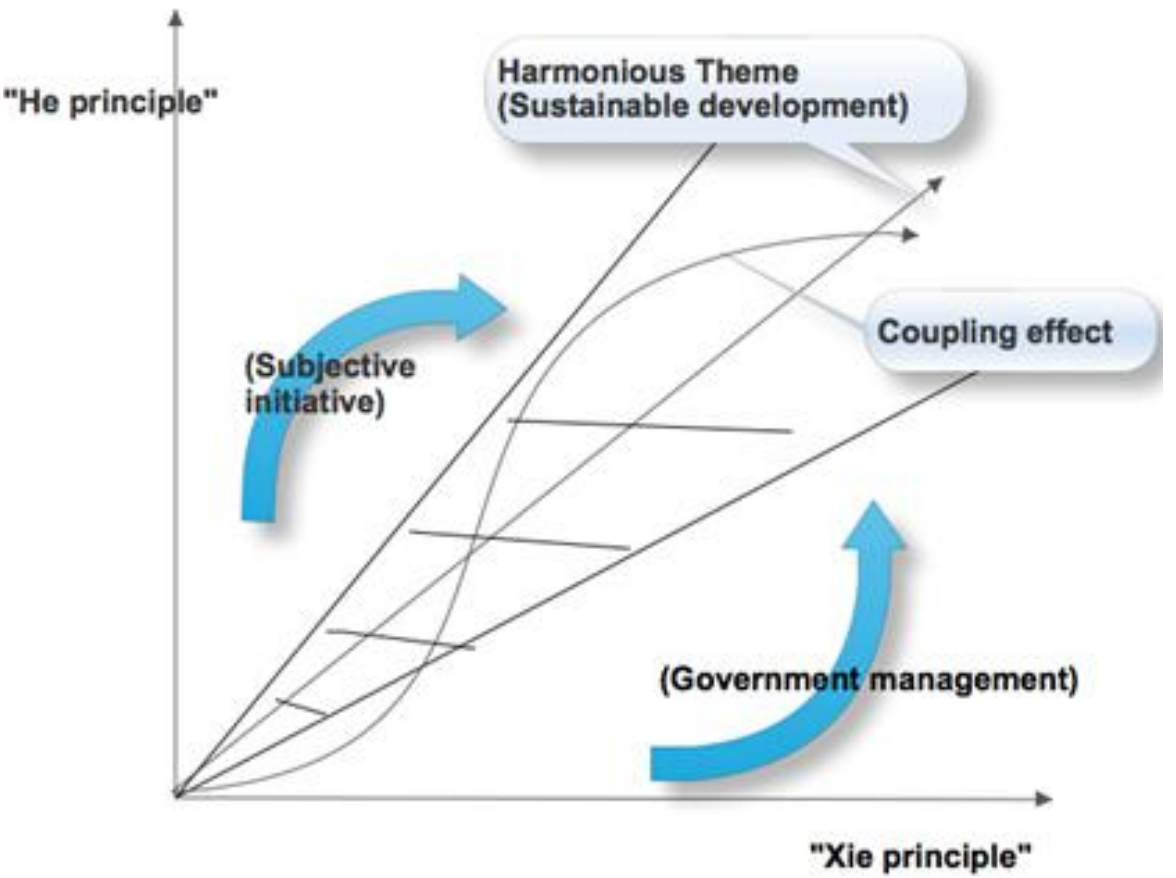

Figure 3. The integration of "dual-principles".

Table 7. The coupling effect of government management and enterprise's subjective initiative.

\begin{tabular}{|c|c|c|}
\hline & Coupling & Content \\
\hline The first level & Interactive & $\begin{array}{l}\text { (1) Using laws and regulations to establish a necessary condition for } \\
\text { HeXie mechanism's development. (2) On the other hand social } \\
\text { opinion and corporate culture can promote the implement of laws } \\
\text { and regulations }\end{array}$ \\
\hline The second level & Interconvertible & $\begin{array}{l}\text { (1) In the procedure of HeXie management, the attitude and } \\
\text { behaviors generated from "He principle" should be absorbed into } \\
\text { government management part so that enriching and strengthening } \\
\text { "Xie principle". (2) With the enhancement of environmental } \\
\text { protection by implement of laws and regulations, government } \\
\text { management becomes enterprise's initiatives. }\end{array}$ \\
\hline The third level & Organic Integration & $\begin{array}{l}\text { (1) Enhancing both government management and enterprise's } \\
\text { subjective initiative simultaneously. (2) The two principles } \\
\text { supplement each other in the process of HeXie management }\end{array}$ \\
\hline
\end{tabular}

terms goal, you have to master systems thinking and pay attention to each elements at the same time. Our conclusion strengthens the practicality of environmental protection and offers a new angle to obtain sustainable development.

\section{REFERENCES}

Adams WM (2006). "The Future of Sustainability: Re-thinking Environment and Development in the Twenty-first Century." Report of the IUCN Renowned Thinkers Meeting, 29-31 January 2006.

Andrew Ure (1835). The Philosophy of Manufactures (London: Chas. Knight 1835), pp.5-8, 14-15, 20-21, 23, 29-31.

Case KE, Fair RC (2006). Principles of Macroeconomics. Prentice Hall.

Claude FB (1851). "Harmonies économiques" Paris.

Coase RH (1974). "The Lighthouse in Economics". J. Law Econ. 17(2):357-376

Coenen FHJM, Fuchs DA, van de Peppel RA (2000). The environment and social well-being: an exploration of facts and figures and of possible relationships. Centre for Clean Technol- ogy and Environmental Policy and Ministry of Housing, Spatial Planning and the Environment. Publicatiereeks milieustrategic (Environmental 
Strategy Publication Series) 2000/6.

Fiegenbaum A, Hart S, Schendel D (1996). Strategic reference point theory. Strateg. Manage. J. 17:219-235.

Hahtola K (1990). Pragmatic-hermeneutical human action model for environmental planning. Hallinnon Tutkimus. Admin. Stud. 9(4):272288.

Hal RV (1991), Microeconomic Analysis, Third ed., Norton Press.

Hart S, Banbury C (1994). 'How strategy-making processes can make a difference'. Srraregic Manage. J. 15(4):251-269.

Hart S, Quinn R (1993). 'Roles executives play: CEOs, behavioral complexity, and firm performance'. Hum. Relat. 46:543-574.

Helmut W, Martin J (2002). Capacity building in national environmental policy: a comparative study of 17 countries, Springer.

Itami H (1987). Mobilizing Invisible Assets, Harvard University Press, Cambridge, MA.

Jared D (2006). Collapse: How Societies Choose to Fail or Succeed. Penguin.

Keynes JM (1936). The General Theory of Employment, Interest, and Money, Harcourt, Brace \& World, 1964.

Kvale S (1996). Interviews An Introduction to Qualitative Research Interviewing, Sage Publications.

Markku L (2004). The environmental-social interface of sustainable development: capabilities, social capital, institutions, Ecol. Econ. 49:199-214.

Mary M (2008). Studies in Social Policy No 23: Reframing the Irish Activation Debate: accommodating care and safeguarding social rights, The Policy Institute, Trinity College, Dublin.

Mas-Colell A, Whinston MD, Green JR (1995). Microeconomic Theory, Oxford University Press. New York.

McNamara C (1999). PhD. General Guidelines for Conducting Interviews, Minnesota.

Michael J (1997). Sustainability and Markets: On the Neoclassical Model of Environmental Economics. New Polit. Econ. 2:3.

Norgaard RB (1994). Development Betrayed: The End of Progress and a Coevolutionary Revisioning of the Future. Routledge, London p.280.
Novek J, Karen K (1992). "Sustainable or Unsustainable Development? An Analysis of an Environmental Controversy". Can. J. Sociol. 17(3):249-273.

Organisation for Economic Co-operation and Development (OECD) (2001b). Policies to enhance sustainable development. Paris.

Ott K (2003). "The Case for Strong Sustainability", In: Ott K \& Thapa P, Greifswald's Environmental Ethicsn, Greifswald: Steinbecker Verlag Ulrich Rose pp.59-64.

Pascale R, Athos A (1981). "The Art of Japanese Management", London: Penguin Books.

Peters T, Waterman R (1982). "In Search of Excellence", New York, London: Harper \& Row.

Quinn R (1988). Beyond Rational Management. Jos-sey-Bass, San Francisco, CA.

Redclift M (1987). Sustainable Development: Exploring the Contradictions. New York, NY: Methuen, Inc.

Shen M, Lu Q (2004). Ecological Conversation and Compensation Mechanism, Zhejiang Learned J. p.4.

Wang Y, Li H, Liu Y (1998). Flexible Thinking of Management. Ann. Oper. Res. (1):22-25.

Waterman R, Peters T, Phillips JR (1980). Structure is not organisation. Bus. Horiz. 23(3):14-26.

Zhang W (2002). The Instructor's Manual for SPSS11. Beijing Hope Press. 